\title{
Pengaruh Model Guided Note Taking (GNT) Terhadap Kecerdasan Emosional Siswa Mata Pelajaran PPkn Kelas V SD Negeri 26 Kota Sorong
}

\author{
Ahmad Yulianto $^{1}$, Elfira Mahmud ${ }^{2} \&$ Rahmah Kumullah $^{3}$ \\ Program Studi PGSD, Universitas Pendidikan Muhammadiyah Sorong, Indonesia \\ Program Studi PGSD, STKIP Andi Mattapa, Indonesia \\ $\bowtie$ E-mail: yuliantoahmad463@gmail.com
}

\begin{abstract}
Abstrak
Penelitian ini bertujuan untuk mendeskripsikan pengaruh model pembelajaran GNT terhadap kecerdasan emosional siswa pada mata pelajaran PPKn kelas V SD Negeri 26 Kota Sorong. Penelitian ini adalah penelitian kuantitatif dengan desain quasi experimental design. Subjek penelitian ini yaitu siswa kelas V SD Negeri 26 Kota Sorong tahun ajaran 2018/2019 yang berjumlah 47 siswa, dimana kelas V A sebanyak 24 siswa dan kelas V B sebanyak 23 siswa. Pengambilan sampel dilakukan dengan teknik sampling yaitu nonprobability sampling. Instrumen penelitian yang digunakan adalah angket dan soal. Teknik analisis data yang digunakan adalah uji normalitas, uji homogenitas dan uji t. Hasil penelitian ini menunjukan bahwa terdapat pengaruh antara model pembelajaran GNT dengan kecerdasan emosional siswa kelas V SD negeri 26 Kota Sorong. Hal ini ditunjukan oleh nilai $t_{\text {hitung }}=$ 3,515 , sedangkan $t_{\text {tabel }}$ pada taraf signifikansi 5\% adalah 2,014. Karena $t_{\text {hitung }}>t_{\text {tabel }}(3,515>2,014)$. Simpulan dalam penelitian ini yaitu terdapat pengaruh pada model pembelajaran GNT terhadap kecerdasan emosional siswa.
\end{abstract}

Kata Kunci: Model pembelajaran; GNT; kecerdasan emosional.

\begin{abstract}
This study aims to describe the influence of the GNT learning model on students' emotional intelligence in PPKn subjects in class V SD Negeri 26 Kota Sorong. This research is a quantitative study with a quasi experimental design. The subjects of this study were grade V students of SD Negeri 26 Kota Sorong in the acadenic year 2018/2019, totaling 47 students, of which there were 24 students in Class V A and 23 students in Class V B. Sampling is done by sampling technique that is nonprobability sampling. The research instruments used were pre-test, post-test and questionnaire. Data analysis techniques used were normality test, homogeneity test and t test. The results of this study indicate that there is a significant influence between the GNT learning model with emotional intelligence of fifth grade students of SD Negeri 26 Kota Sorong. This is indicated by the $t_{\text {count }}=$ 3.515 , while the table at the $5 \%$ significance level is 2.014 . Because $t_{\text {count }}>t_{\text {table }}(3,515>2,014)$. The conclusion of this research is what is meant by the GNT learning model on students' emotional intelligence.
\end{abstract}

Keywords: Learning Model; GNT; Emotional intelligence. 


\section{PENDAHULUAN}

Kemajuan suatu bangsa terletak pada bidang pendidikan. Pendidikan pada hakikatnya ialah untuk memanusiakan manusia itu sendiri. Di Indonesia sekarang ini sedang dihadapkan dengan masalah mutu pendidikan yang masih tergolong rendah (Thaib, 2013). Hal ini bisa dilihat dari hasil yang diperoleh dari data (Programme for International Student Assessment) PISA tahun 2015 menunjukkan bahwa dari 70 negara yang disurvei, negara Indonesia berada pada peringkat ke 62 dalam bidang literasi bacaan, matematika dan sains (OECD, 2015). Kualitas pendidikan yang sangat rendah ini tidak menyurutkan semangat pemerintah untuk meningkatkan mutu pendidikan di Indonesia.

Berbagai usaha telah dilakukan untuk meningkatkan mutu pendidikan, diantaranya pengembangan kurikulum, peningkatan kompetensi guru, pengadaan buku dan sarana pendidikan lain serta perbaikan manajemen sekolah (Gusniwati, 2015). Selain itu seiring dengan tujuan pendidikan nasional yaitu mencerdaskan kehidupan bangsa dan mengembangkan manusia Indonesia seutuhnya, yaitu manusia yang beriman dan bertaqwa terhadap Tuhan Yang Maha Esa dan berbudi pekerti luhur, memiliki pengetahuan dan keterampilan, kesehatan jasmani dan rohani, kepribadian yang mantap dan mandiri, serta tanggung jawab kemasyarakatan dan berbangsa, Indonesia terus berbenah dan mengembangkan berbagai strategi untuk meningkatkan keberhasilan peserta didik

Berbagai aspek penilaian digunakan oleh pendidik untuk mengukur keberhasilan peserta didik, salah satunya adalah Intelligence Quotient (IQ). IQ yang tinggi menjadi tuntutan utama yang harus dimiliki oleh setiap peserta didik sebagai tolak ukur prestasi belajar (Thaib, 2013). Kenyataannya dalam belajar mengajar disekolah sering ditemukan siswa yang tidak dapat meraih prestasi belajar yang setara dengan kemampuan intelegensinya (Pamungkas, Suhartono, \& Chrysti, 2016). Ada siswa yang mempunyai kemampuan intelegensi tinggi tetapi memperoleh prestasi belajar yang relative rendah, namun ada siswa yang memiliki kemampuan intelegensi relative rendah, dapat meraih prestasi belajar yang relative tinggi (Gusniwati, 2015). Hal ini sangat jelas bahwa intelegensi bukan merupakan satu-satunya faktor yang menentukan keberhasilan peserta didik (Fahrurrozi \& Mahmudi, 2014).

IQ hanya menyumbang $20 \%$ bagi kesuksesan seseorang, sedangkan $80 \%$ adalah sumbangan dari faktor-faktor lain, diantaranya EQ yaitu kemampuan memotivasi diri sendiri, mengatasi frustasi, mengontrol desakan hati, mengatur suasana hati, berempati serta kemampuan bekerjasama (Goleman, 2018). Dalam proses belajar, EQ dan IQ sangat dibutuhkan (Wahyuni, Budiyono, \& Sujadi, 2014). IQ tidak dapat berfungsi dengan baik tanpa partisipasi dari penghayatan emosional terhadap mata pelajaran yang disampaikan disekolah (Fahrurrozi \& Mahmudi, 2014). Keseimbangan IQ dan EQ merupakan kunci keberhasilan belajar siswa di sekolah. Oleh karena itu IQ dan EQ merupakan satu komponen yang harus dikembangkan bersama sebagai penunjang keberhasilan peserta didik.

Hasil belajar tidak hanya dipengaruhi oleh faktor internal, tetapi dipengaruhi juga oleh faktor eksternal. Faktor eksternal adalah faktor yang berasal dari luar diri peserta didik diantaranya adalah jenis model pembelajaran yang digunakan guru (Pamungkas et al., 2016). Guru cenderung menggunakan model pembelajaran yang konvensional yang membuat siswa bosan dalam pembelajaran (Sundari, Usada, \& Matsuri, 2012). Hal ini mengakibatkan tidak terciptanya suasana belajar yang aktif dan kreatif. Pembelajaran yang konvensional ini membuat siswa tidak memiliki semangat dan motivasi belajar.

Hasil observasi yang dilakukan di SD Negeri 26 Kota Sorong pada tanggal 17 sampai 19 Januari 2019 diketahui bahwa sebagian besar guru-guru di sekolah tersebut masih menggunakan model ceramah tanpa dilengkapi dengan strategi pembelajaran lain, 
mengakibatkan kurangnya aktifitas siswa dalam belajar. Siswa hanya terfokus mendengarkan penjelasan dari guru tanpa ada aktifitas lain yang memacu motivasi siswa untuk meningkatkan kreatifitas dalam belajar. Pembelajaran yang monoton ini mengakibatkan kurangnya interaksi antara sesama siswa sehingga siswa tidak memiliki kepercayaan diri dalam mengeluarkan pendapat atau memberikan pertanyaan terkait materi yang tidak dimengerti. Terkait dengan masalah kesulitan siswa maka perlu diterapkan suatu model pembelajaran yang dapat membangkitkan dan melibatkan kemampuan bekerja sama siswa dalam kegiatan belajar mengajar. Salah satunya adalah model pembelajaran Guided Note Taking (GNT).

Model pembelajaran GNT merupakan model pembelajaran menggunakan handout yang di dalamnnya terdapat poin-poin penting yang sengaja dikosongkan. Model GNT memudahkan siswa menangkap materi yang akan diajarkan karena guru terlebih dahulu akan memberikan handout dari materi (Musyahidin \& Kholis, 2015). Pembelajaran tipe guided note taking adalah salah satu model pembelajaran yang memungkinkan guru maupun siswa untuk sama-sama aktif terlibat dalam kegiatan pembelajaran. Model pembelajaran GNT menuntut guru untuk mempersiapkan suatu bagan, skema atau yang lain guna membantu siswa dalam membuat catatan selama pembelajaran (Hartanto, Mahfud, \& Sadiman, 2015). Melalui model GNT siswa dapat meningkatkan kecakapan menyimak, mendengar, dan berkonsentrasi.

Secara etimologi GNT terdiri dari 3 kata yakni guide, note dan taking. Guided berasal dari kata guide berarti buku panduan, pedoman, note berarti catatan dan taking berasal dari take mempunyai arti pengambilan. Jadi GNT adalah penggambilan catatan terbimbing (Yulianto, 2017). Secara terminologi GNT atau catatan terbimbing merupakan model dimana siswa diberikan suatu bagan, skema sebagai media yang dapat membantu siswa dalam membuat catatan ketika seorang guru menyampaikan pelajaran.

Model pembelajaran GNT merupakan model pembelajaran menggunakan handout yang di dalamnnya terdapat poin-poin penting yang sengaja dikosongkan (Christianti, Sudarmin, \& Subroto, 2012). Model pembelajaran GNT meminta siswa berkonsentrasi pada pembelajaran untuk mengisi poin-poin kosong dari handout yang diberikan, sehingga dalam pembelajaran siswa tidak hanya mendengarkan atau mencatat, dan setelah penyampaian materi dengan ceramah selesai, siswa diminta untuk membacakan atau mengumpulkan handoutnya. Berdasarkan uraian diatas dapat disimpulkan bahwa model pembelajaran GNT merupakan suatu model pembelajaran dalam bentuk catatan terbimbing, dimana catatan yang diberikan berisi poin-poin penting yang sengaja dikosongkan sehingga siswa akan berkosentrasi mendengarkan materi yang disampaikan agar bisa mengisi catatan atau handout yang diberikan. Adapun langkah-langkah model GNT menurut (Suprijono, 2009) adalah (a) Setiap siswa diberi rangkuman dari materi pelajaran yang akan disampaikan guru. (b) Guru mengosongkan sebagian dari poin-poin yang dianggap penting, sehingga akan terdapat bagian-bagian yang kosong dalam rangkuman tersebut, (c) Guru menjelaskan bahwa bahan ajar atau rangkuman sengaja dihilangkan beberapa poin agar siswa tetap berkosentrasi mendengarkan pelajaran yang akan guru sampaikan agar dapat melengkapi bahan ajar dengan tepat, (d) Setelah selesai menyampaikan materi, siswa diminta untuk membacakan hasil kerja pada rangkuman yang diberikan.

Kecerdasan emosinal merupakan kemampuan siswa untuk mengenali emosi diri, mengelola emosi diri dan mengenali emosi orang lain, memotivasi diri sendiri serta kemampuan menjalin hubungan dengan orang lain (Vebri, 2018). Melalui kecerdasan emosional siswa dapat mengontrol dirinya, mampu berkomunikasi baik dengan orang lain dan dapat mempengaruhi berkembangnya kemampuan kognitif siswa (Ardana, Aritonang, \& Dermawan, 2013; 
Pangastuti, Johan, \& Kurniasari, 2014).

Berdasarkan uraian diatas dapat disimpulkan bahwa kecerdasan emosional adalah kemampuan yang mencakup pengenalan emosi baik untuk diri sendiri maupun orang lain, pengendalian diri, mampu memahami perasaan orang lain, dapat menjalin hubungan baik dengan orang lain serta dapat memotivasi diri untuk melakukan hal-hal yang terarah.

\section{METODE PENELITIAN}

Penelitian ini dilaksanakan di SD Negeri 26 Kota Sorong yang terletak di jalan Jenderal Sudirman no. 24. Subjek penelitian yaitu siswa kelas V SD Negeri 26 Kota Sorong semester genap tahun ajaran 2018/2019. Kelas V SD Negeri 26 Kota Sorong merupakan kelas paralel yang terdiri dari dua kelas yaitu kelas $\mathrm{V}$ A dan V B dengan jumlah 47 siswa, dimana kelas $\mathrm{V}$ A sebanyak 24 dan kelas V B sebanyak 23 siswa.

Penelitian ini merupakan quasi eksperimental design yang menggunakan dua kelas, yaitu kelas eksperimen dan kelas kontrol. Model pembelajaran untuk kelas eksperimen menggunakan model pembelajaran GNT, dan untuk kelas kontrol diberikan pembelajaran dengan model pembelajaran yang biasa digunakan oleh guru dalam mengajar yaitu dengan pendekatan saintifik dan metode ceramah sebagai penguatan. Untuk menentukan kelas eksperimen dan kelas kontrol, peneliti melakukan pengundian sederhana dan ditetapkan kelas V A sebagai kelas eksperimen dan kelas V B sebagai kelas kontrol. Selanjutnya masing-masing kelas diberikan pre test, angket dan post test.

\section{HASIL DAN PEMBAHASAN}

Hasil uji normalitas diperoleh jumlah (N) pada kelas eksperimen adalah 24 siswa dan kelas kontrol 23 siswa. Rata-rata (Mean) dari kelas eksperimen adalah 79,75 dan kelas kontrol 71, 43. Standar deviasi dari kelas eksperimen adalah 9,195 dan kelas kontrol adalah 6,788. Difference positive dari kelas eksperimen adalah 0,197 dan kelas kontrol

adalah 0,236. Difference negative untuk kelas eksperimen adalah -0,144 dan untuk kelas kontrol -0,114. Kolmogorof-smirnov kelas eksperimen adalah 0,966 dan kelas kontrol 1,131. Kemudian berdasarkan perhitungan diatas dengan menggunakan kolmogorof-smirnov dapat disimpulkan bahwa rata-rata berdistribusi normal karena memiliki Asymp,Sig > 0,05 hasil belajar kelas eksperimen memiliki sig sebesar 0,308 dan kelas kontrol sebesar 0,155 sehingga dapat disimpulkan bahwa data tersebut berdistribusi normal. Lebih lengkap disajikan pada tabel 1 .

Tabel 1. Hasil perhitungan normalitas data

\begin{tabular}{|c|c|c|}
\hline \multicolumn{3}{|c|}{ One-Sample Kolmogorov-Smirnov Test } \\
\hline & $\begin{array}{l}\text { kelas } \\
\text { eksperi } \\
\text { men }\end{array}$ & $\begin{array}{l}\text { kelas } \\
\text { kontrol }\end{array}$ \\
\hline $\mathrm{N}$ & 24 & 23 \\
\hline \multirow{2}{*}{$\begin{array}{l}\text { Normal } \\
\text { Parameters }^{\mathrm{a}}\end{array}$} & 96.29 & 91.57 \\
\hline & 5.513 & 6.148 \\
\hline \multirow{3}{*}{$\begin{array}{l}\text { Most Extrem } \\
\text { Differences }\end{array}$} & .116 & .156 \\
\hline & .116 & .122 \\
\hline & -.085 & -.156 \\
\hline \multirow{2}{*}{$\begin{array}{l}\text { Kolmogorov-Smirnov Z } \\
\text { Asymp. Sig. (2-tailed) } \\
\text { a. Test distribution is Normal. }\end{array}$} & .566 & .748 \\
\hline & .906 & .631 \\
\hline
\end{tabular}

\section{post test}

One-Sample Kolmogorov-Smirnov Test

\begin{tabular}{|c|c|c|c|}
\hline & & $\begin{array}{l}\text { kelas } \\
\text { eksperi } \\
\text { men }\end{array}$ & $\begin{array}{l}\text { kelas } \\
\text { kontrol }\end{array}$ \\
\hline \multicolumn{2}{|l|}{$\mathrm{N}$} & 24 & 23 \\
\hline \multirow{2}{*}{$\begin{array}{l}\text { Normal } \\
\text { Parameters }\end{array}$} & Mean & 79.75 & 71.43 \\
\hline & $\begin{array}{l}\text { Std. } \\
\text { Deviation }\end{array}$ & 9.195 & 6.788 \\
\hline \multirow{3}{*}{$\begin{array}{l}\text { Most Extreme } \\
\text { Differences }\end{array}$} & Absolute & .197 & .236 \\
\hline & Positive & .197 & .236 \\
\hline & Negative & -.144 & -.114 \\
\hline \multicolumn{2}{|c|}{ Kolmogorov-Smirnov Z } & .966 & 1.131 \\
\hline \multicolumn{2}{|c|}{ Asymp. Sig. (2-tailed) } & .308 & .155 \\
\hline
\end{tabular}




\begin{tabular}{|c|c|c|c|}
\hline \multicolumn{4}{|c|}{ One-Sample Kolmogorov-Smirnov Test } \\
\hline & $\begin{array}{l}\text { kelas } \\
\text { eksperi } \\
\text { men }\end{array}$ & $\begin{array}{l}\text { kelas } \\
\text { kontrol }\end{array}$ \\
\hline \multicolumn{2}{|l|}{$\mathrm{N}$} & 24 & 23 \\
\hline \multirow{2}{*}{$\begin{array}{l}\text { Normal } \\
\text { Parameters }\end{array}$} & Mean & 79.75 & 71.43 \\
\hline & $\begin{array}{l}\text { Std. } \\
\text { Deviation }\end{array}$ & 9.195 & 6.788 \\
\hline \multirow{3}{*}{$\begin{array}{l}\text { Most Extrem } \\
\text { Differences }\end{array}$} & e Absolute & .197 & .236 \\
\hline & Positive & .197 & .236 \\
\hline & Negative & -.144 & -.114 \\
\hline \multicolumn{2}{|c|}{ Kolmogorov-Smirnov Z } & 966 & 1.131 \\
\hline \multicolumn{2}{|c|}{ Asymp. Sig. (2-tailed) } & .308 & .155 \\
\hline
\end{tabular}

Pengolahan data uji normalitas diperoleh dari perhitungan menggunakan SPSS V16.0 Statistic For Windows diketahui hasil belajar post test dan data kecerdasan emosional yaitu untuk data pos test kelas eksperimen memiliki sig sebesar 0,308, kelas kontrol sebesar 0,155 dan untuk data kecerdasan emosional kelas eksperimen memiliki sig sebesar 0,906, kelas kontrol sebesar 0,631 dimana Asymp,Sig > 0,05 sehingga dapat disimpulkan bahwa kelas $\mathrm{V}$ berdistribusi normal dan data layak digunakan untuk uji selanjutnya, yaitu uji homogenitas.

Pengujian homogenitas diketahui bahwa nilai signifikansinya adalah 0,217 . Karena nilai signifikansinya lebih besar dari 0,05 sehingga dapat disimpulkan bahwa data kecerdasan emosional tersebut homogen. Lebih jelasnya disajikan pada tabel 2.

Tabel 2. Hasil Perhitungan Homogenitas Data Kecerdasan Emosional

\section{Test of Homogeneity of Variances}

kecerdasan emosional

\begin{tabular}{llll}
\hline $\begin{array}{l}\text { Levene } \\
\text { Statistic }\end{array}$ & df1 & df2 & Sig. \\
\hline 1.569 & 1 & 45 & .217 \\
\hline
\end{tabular}

Pada uji homogenitas diketahui data post test kelas eksperimen dan kelas kontrol nilai signifikansinya adalah 0,102 dan data kecerdasan emosional memiliki nilai signifikansi $\quad 0,217$. Karena nilai signifikansinya lebih besar dari 0,05 yaitu $0,102>0,05$ dan $0,217>0,05$ maka data tersebut dapat dikatan homogen dan dapat digunakan untuk uji selanjutnya, yaitu uji hipotesis.

Hasil uji hipotesis menggunakan uji $\mathrm{t}$ sehingga diketahui nilai $t_{\text {hitung }}$ sebesar 3,515 dengan $\mathrm{dk}=\mathrm{n}-2(47-2=45)$ diperoleh $\mathrm{t}_{\text {tabel }}$ sebesar 2,014. Berdasarkan hasil analisis data nilai yaitu $t_{\text {hitung }}>t_{\text {tabel }}(3,515>2,014)$, ini berarti bahwa $t_{\text {hitung }}$ lebih besar dari tabel pada taraf 5\% sehingga hipotesis dalam penelitian ini diterima dan dapat disimpulkan bahwa terdapat pengaruh antara model pembelajaran GNT terhadap kecerdasan emosional di SD Negeri 26 Kota Sorong. Lebih lengkap bisa dilihat pada tabel 3 .

Tabel 3. Hasil Perhitungan Uji $\mathrm{T}$ Data Kecerdasan Emosional

Independent Samples Test

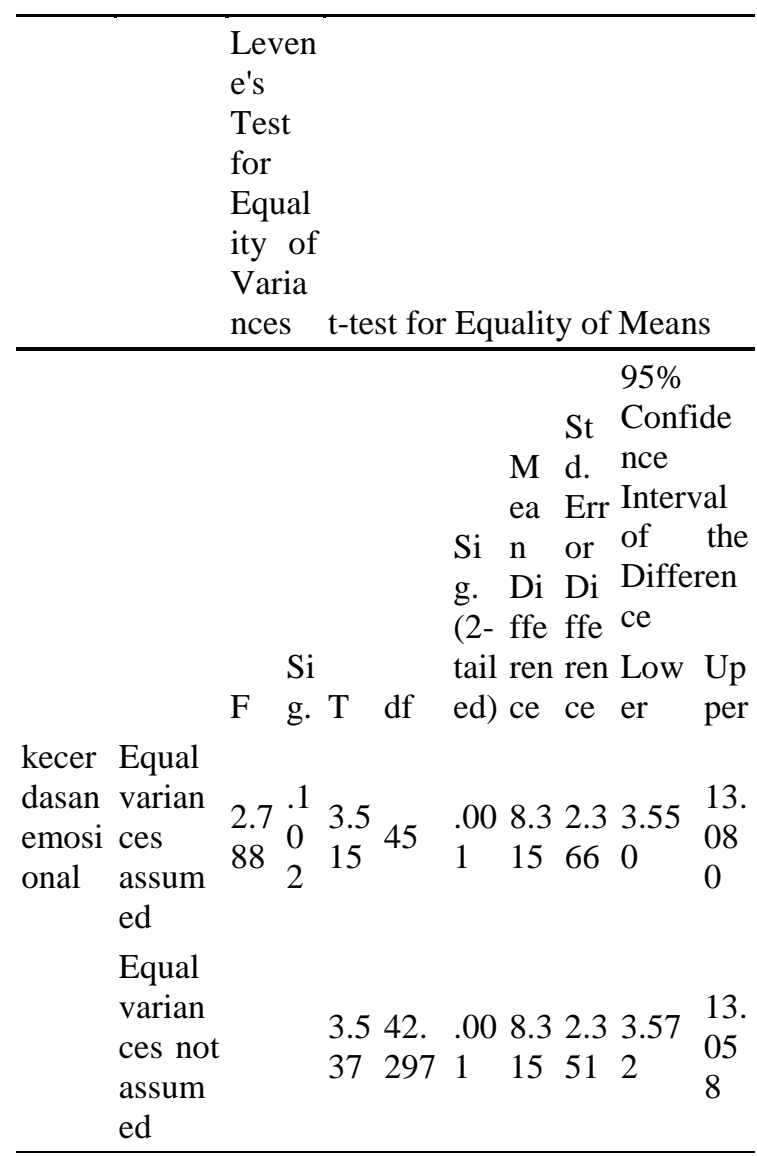

Dari hasil pengujian hipotesis 
menggunakan uji independet sample test dimana data yang diuji yaitu hasil data kecerdasan emosional dari kelas eksperimen dan kelas kontrol diperoleh $t_{\text {hitung }}$ sebesar 3,515 dengan $\mathrm{dk}=\mathrm{n}-1(47-2=45)$ diperoleh $\mathrm{t}_{\text {tabel }}$ sebesar 2,014. Berdasarkan hasil analisis data nilai yaitu $t_{\text {hitung }}>t_{\text {tabel }}(3,515>2,014)$ maka hipotesis diterima dan dapat disimpulkan bahwa terdapat pengaruh model pembelajaran GNT terhadap kecerdasan emosional siswa kelas V SD Negeri 26 Kota Sorong pada Tahun Ajaran 2018/2019.

\section{KESIMPULAN}

Berdasarkan rumusan masalah dari hipotesis yang diajukan, serta hasil penelitian yang didasarkan pada analisis data dan pengujian hipotesis, maka kesimpulan yang dapat dikemukakan dalam penelitian ini yaitu terdapat pengaruh pada model pembelajaran GNT terhadap kecerdasan emosional siswa kelas V SD negeri 26 Kota Sorong pada tahun ajaran 2018/2019. Hal ini ditunjukan oleh nilai $t_{\text {hitung }}=3,515$, sedangkan $t_{\text {tabel }}$ pada taraf signifikansi 5\% adalah 2,014. Karena $t_{\text {hitung }}>t_{\text {tabel }}(3,515>2,014)$ maka Hipotesis diterima.

\section{DAFTAR RUJUKAN}

Ardana, I. C., Aritonang, L. R., \& Dermawan, E. S. (2013). Kecerdasan Intelektual, Kecerdasan Emosional, Kecerdasan Spiritual, dan Kesehatan Fisik Untuk Memprediksi Prestasi Belajar Mahasiswa Akuntansi, XVII(03), 444-458.

Christianti, Sudarmin, \& Subroto, T. (2012). Model Pembelajaran Guided Note Taking Berbantuan. Jurnal Pendidikan IPA Indonesia, 1(1), 27-31. https://doi.org/http://dx.doi.org/10.1529 4/jpii.v1i1.2009

Fahrurrozi, \& Mahmudi, A. (2014). Pengaruh PBM dalam Setting Pembelajaran Kooperatif Tipe STAD dan GI ... ( Fahrurrozi, Ali Mahmudi ) $1,1,1-11$.

Goleman, D. (2018). Emotional Inteligence: Kecerdasan Emosional. Jakarta: PT Gramedia Pustaka Utama.
Gusniwati, M. (2015). Pengaruh Kecerdasan Emosional Dan Minat Belajar, 5(1), 2641

https://doi.org/http://dx.doi.org/10.3099 8/formatif.v5i1.165

Hartanto, D., Mahfud, H., \& Sadiman. (2015). Penerapan Metode Guided Note Taking Untuk Meningkatkan Pemahaman Konsep Proklamasi Kemerdekaan Republik Indonesia, 1-6.

Musyahidin, A. S., \& Kholis, N. (2015). Pengaruh Perpaduan Model Pembelajaran Kooperatif Tipe Think Pair Share Dengan Metode Guided Note Taking Terhadap Hasil Belajar Siswa Pada Standar Kompetensi Memperbaiki Cd Player Kelas Xi Tav Di Smk Negeri 2 Surabaya, 04.

OECD. (2015). Pisa 2015 Result In Focus, (853).

Pamungkas, R., Suhartono, \& Chrysti, K. (2016). Pengaruh Kecerdasan Emosioal Terhadap Hasil Belajar Matematika pada Siswa Kelas V SD Se-Kecamatan Prembun. https://doi.org/10.1111/j.13652745.2009.01572.x

Pangastuti, L., Johan, A., \& Kurniasari, I. (2014). Profil Kemampuan Komunikasi Matematika Siswa SMP Ditinjau Dari Kecerdasan Emosional. Mathedunesa Jurnal Ilmiah Pendidikan Matematika, $3(2)$.

Sundari, E., Usada, \& Matsuri. (2012). Penggunaan Metode Guided Note Taking Untuk Meningkatkan Hasil Belajar IPS Materi Masalah Sosial, 1-4.

Suprijono, A. (2009). Cooperative Learning: Teori Dan Aplikasi PAIKEM. Yohyakarta: Pustaka Belajar.

Thaib, E. N. (2013). Hubungan antara Prestasi Belajar dengan Kecerdasan Emosional, XIII(2), 384-399.

Vebri, N. A. (2018). Analisis Kemampuan Komunikasi Matematika Siswa dalam Menyelesaikan Permasalahan Ukuran Pemusatan Data Ditinjau dari Kecerdasan Emosional.

Wahyuni, E. T., Budiyono, B., \& Sujadi, I. (2014). Eksperimentasi Model 
Pembelajaran Kooperatif Tipe Numbered Heads Together (NHT) dan Think Pair Share (TPS) pada Materi Pokok Trigonometri Ditinjau dari Kecerdasan Emosional Siswa SMK di Kota Madiun Tahun Pelajaran 2013/2014. Jurnal Pembelajaran Matematika, 2(6), 558-567. Retrieved from http://jurnal.fkip.uns.ac.id/index.php/s2 math/article/view/4504

Yulianto, A. (2017) Menjaga Konsentrasi Siswa Fokus Pada Materi Dengan Metode Guided Note Talking (GNT). In Susunan Redaksi Seminar Nasional "Tellu Cappa" (p. 14). 